\title{
In memoriam: Dr. Giovanni Serafini, MD
}

\author{
Luca Maria Sconfienza ${ }^{1,2}$ (D)
}

Received: 31 March 2020 / Accepted: 1 April 2020 / Published online: 17 April 2020

(c) Società Italiana di Ultrasonologia in Medicina e Biologia (SIUMB) 2020

Keywords Obituary $\cdot$ Musculoskeletal radiology $\cdot$ Urogenital radiology $\cdot$ Ultrasonography

With the loss of Dr. Giovanni Serafini, MD on March 4, 2020, the Italian and international medical community has lost one of its greatest masters.

Giovanni Serafini graduated with honors in Medicine and Surgery from the University of Genoa, Italy in 1978 and specialized with honors in Radiology at the same University in 1981. He joined the Radiology Unit of the S. Paolo Civil Hospital of Savona in 1979, under the direction of Professor De Albertis. In 1995, he moved to the Radiology Unit of the S. Corona Hospital, Pietra Ligure, Italy, where he became Director in 1998 up to 2016, the year of his retirement. He has been adjunct professor of Urogenital Radiology at the School of Specialization in Radiology of the Faculty of Medicine of the University of Genoa since 2000 and for Radiology and related tutorial activities at the Faculty of Medicine and Surgery of the University of Genoa since 2004. He has been a member of the Board of Directors of the Urogenital Radiology section of the Italian Society of Medical Radiology and has published over 75 scientific articles in indexed journals (Fig. 1).

Endowed with an uncommon curiosity and intelligence, Giovanni Serafini started his activity in the field of ultrasonography, when this imaging method was in its very early days and had just been introduced in the local radiological community [1]. From these first steps, he immediately became a Master in ultrasonography of all body districts, devoting himself with exceptional interest to urogenital pathology and interventional ultrasound. He also dedicated himself to areas of ultrasonography that over time have

Luca Maria Sconfienza

io@lucasconfienza.it

1 Dipartimento Di Scienze Biomediche Per La Salute, Università Degli Studi Di Milano, Via Pascal 36, 20100 Milan, Italy

2 IRCCS Istituto Ortopedico Galeazzi, Milan, Italy become the prerogative of other medical specialties, such as ocular [2-4] and obstetric ultrasound.

First in the world, in the mid-1990s, Giovanni Serafini developed the technique of ultrasound-guided percutaneous irrigation of calcific tendinopathy of the shoulder using two needles, modifying the fluoroscopic approach described in 1978 and opening the way to the treatment of such a widespread and painful pathology especially in young women [5-10]. This idea led him to be known in Italy and worldwide as the leading expert on the topic, with the publication of three papers in the journal Radiology [11-13], others in many international journals [5-10] and a press conference in 2007 during the Annual Congress of the Radiological Society of North America (RSNA).

Giovanni Serafini has lectured at countless national and international conferences, sharing with colleagues also from other specialties his boundless knowledge in the ultrasound field. In addition, he has been the mentor of hundreds of radiology and non-radiology residents who have always struggled to get the possibility of attending his department in Pietra Ligure. For them, Giovanni Serafini lavished an untiring and irrepressible energy, at all hours of the day (and night!), well beyond the tasks required by his university duties. Even older colleagues, coming from all over Italy, crowded into his clinic in search of advice and tricks, of which he was always prodigal.

Today, the Italian and international radiological and ultrasound communities have lost their indomitable and volcanic master. Our work will suffer from an enormous void, which has been filled until today by an exceptional master, a guide, a friend. It will now be our responsibility to ensure that the outstanding scientific and cultural heritage left by Giovanni Serafini continues to grow, give fruit, and be spread, as he loved to do. We will miss him immensely, but we will keep in our hearts all his teachings, which have been of life even before radiology. 


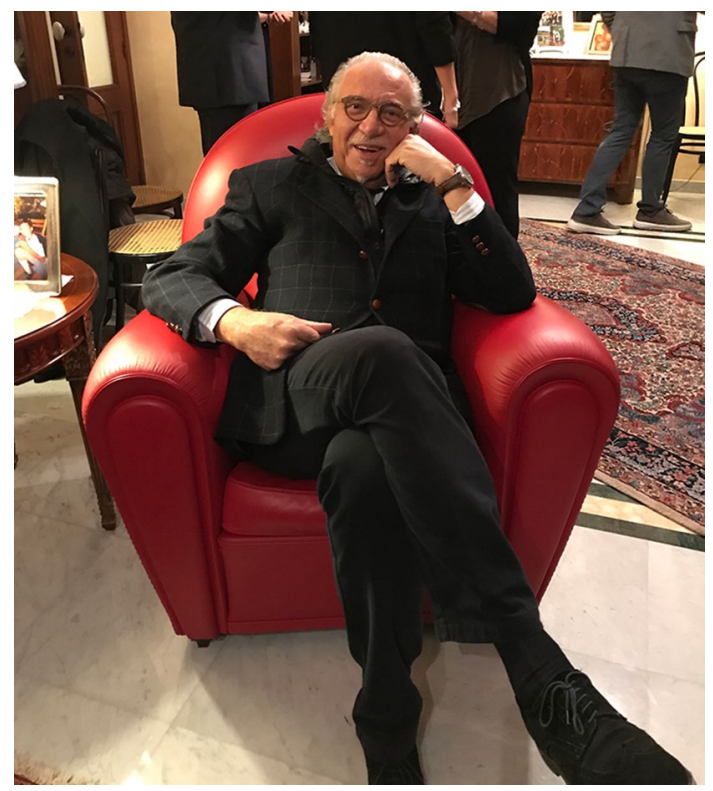

Fig. 1 Dr. Giovanni Serafini, MD, 1952-2020

He leaves his wife, Dr. Nicoletta Gandolfo, MD, radiologist and great friend, and three children. Together with them, his many fellows will keep the wonderful memory of Giovanni Serafini very high.

\section{References}

1. Venturino G, Serafini G, Stellatelli M, Cavallo L (1984) Some observations on echotomography in subcutaneoustendonsprains| [alcune considerazioni sull'indagine ecotomografica nelle fratture tendinee sottocutanee]. Minerva Ortopedica 35:11-17

2. Bertolotto M, Serafini G, Sconfienza LM, Lacelli F, Cavallaro M, Coslovich A, Tognetto D, Cova MA (2014) The use of CEUS in the diagnosis of retinal/choroidal detachment and associated intraocular masses-preliminary investigation in patients with equivocal findings at conventional ultrasound. Ultraschall Med 35(2):173-180. https://doi.org/10.1055/s-0032-1330321

3. Sconfienza LM, Lacelli F, Ardemagni A, Perrone N, Bertolotto M, Padolecchia R, Serafini G (2010) High-resolution, threedimensional, and contrast-enhanced ultrasonographic findings in diseases of the eye. J Ultrasound 13(4):143-149. https://doi. org/10.1016/j.jus.2010.10.002
4. Orlandi D, Sconfienza LM, Lacelli F, Bertolotto M, Sola S, Mauri G, Savarino E, Serafini G (2013) Ultrasound-guided core-needle biopsy of extra-ocular orbital lesions. Eur Radiol 23(7):19191924. https://doi.org/10.1007/s00330-013-2776

5. Sconfienza LM, Serafini G, Sardanelli F (2011) Treatment of calcific tendinitis of the rotator cuff by ultrasound-guided singleneedle lavage technique. AJR Am J Roentgenol 197(2):W366. https://doi.org/10.2214/AJR.10.6295(author reply 367)

6. Cacchio A, Rompe JD, Serafini G, Sconfienza LM, Sardanelli F (2010) US-guided percutaneous treatment of shoulder calcific tendonitis: some clarifications are needed. Radiology 254(3):990. https://doi.org/10.1148/radiol.091542(author reply 990-1)

7. Messina C, Banfi G, Orlandi D, Lacelli F, Serafini G, Mauri G, Secchi F, Silvestri E, Sconfienza LM (2016) Ultrasound-guided interventional procedures around the shoulder. Br J Radiol 89(1057):20150372. https://doi.org/10.1259/bjr.20150372

8. Lanza E, Banfi G, Serafini G, Lacelli F, Orlandi D, Bandirali M, Sardanelli F, Sconfienza LM (2015) Ultrasound-guided percutaneous irrigation in rotator cuff calcific tendinopathy: what is the evidence? A systematic review with proposals for future reporting. Eur Radiol 25(7):2176-2183. https://doi.org/10.1007/s0033 0-014-3567-1

9. Orlandi D, Fabbro E, Mauri G, Savarino E, Serafini G, Sconfienza LM (2013) RE: a Simple technique to restore needle patency during percutaneous lavage and aspiration of calcific rotator cuff tendinopathy. PMR 5(7):633. https://doi.org/10.1016/j. pmrj.2013.04.018

10. Sconfienza LM, Viganò S, Martini C, Aliprandi A, Randelli P, Serafini G, Sardanelli F (2013) Double-needleultrasound-guidedpercutaneous treatment of rotator cuffcalcifictendinitis: tips \& tricks. Skeletal Radiol 42(1):19-24. https://doi.org/10.1007/s0025 6-012-1462-x

11. Serafini G, Sconfienza LM, Lacelli F, Silvestri E, Aliprandi A, Sardanelli F (2009) Rotator cuff calcific tendonitis: short-term and 10 -year outcomes after two-needle us-guided percutaneous treatment-nonrandomized controlled trial. Radiology 252(1):157-164. https://doi.org/10.1148/radiol.2521081816

12. Sconfienza LM, Bandirali M, Serafini G, Lacelli F, Aliprandi A, Di Leo G, Sardanelli F (2012) Rotator cuff calcific tendinitis: does warm saline solution improve the short-term outcome of doubleneedle US-guided treatment? Radiology 262(2):560-566. https:// doi.org/10.1148/radiol.11111157

13. Orlandi D, Mauri G, Lacelli F, Corazza A, Messina C, Silvestri E, Serafini G, Sconfienza LM (2017) Rotator cuff calcific tendinopathy: randomized comparison of US-guided percutaneous treatments by using one or two needles. Radiology 285(2):518-527. https://doi.org/10.1148/radiol.2017162888

Publisher's Note Springer Nature remains neutral with regard to jurisdictional claims in published maps and institutional affiliations. 